Louisiana State University

LSU Digital Commons

Faculty Publications

Department of Chemistry

3-21-2018

\title{
Solution Self-Assemblies of Sequence-Defined Ionic Peptoid Block Copolymers
}

\author{
Garrett L. Sternhagen \\ Louisiana State University \\ Sudipta Gupta \\ Louisiana State University \\ Yueheng Zhang \\ Tulane University \\ Vijay John \\ Tulane University \\ Gerald J. Schneider \\ Louisiana State University
}

See next page for additional authors

Follow this and additional works at: https://digitalcommons.Isu.edu/chemistry_pubs

\section{Recommended Citation}

Sternhagen, G., Gupta, S., Zhang, Y., John, V., Schneider, G., \& Zhang, D. (2018). Solution Self-Assemblies of Sequence-Defined Ionic Peptoid Block Copolymers. Journal of the American Chemical Society, 140 (11), 4100-4109. https://doi.org/10.1021/jacs.8b00461

This Article is brought to you for free and open access by the Department of Chemistry at LSU Digital Commons. It has been accepted for inclusion in Faculty Publications by an authorized administrator of LSU Digital Commons.

For more information, please contact ir@lsu.edu. 
Authors

Garrett L. Sternhagen, Sudipta Gupta, Yueheng Zhang, Vijay John, Gerald J. Schneider, and Donghui Zhang 
Louisiana State University

LSU Digital Commons

Faculty Publications

Department of Chemistry

3-21-2018

\title{
Solution Self-Assemblies of Sequence-Defined Ionic Peptoid Block Copolymers
}

\author{
Garrett L. Sternhagen \\ Louisiana State University \\ Sudipta Gupta \\ Louisiana State University \\ Yueheng Zhang \\ Tulane University \\ Vijay John \\ Tulane University \\ Gerald J. Schneider \\ Louisiana State University
}

See next page for additional authors

Follow this and additional works at: https://digitalcommons.Isu.edu/chemistry_pubs

\section{Recommended Citation}

Sternhagen, G., Gupta, S., Zhang, Y., John, V., Schneider, G., \& Zhang, D. (2018). Solution Self-Assemblies of Sequence-Defined Ionic Peptoid Block Copolymers. Journal of the American Chemical Society, 140 (11), 4100-4109. https://doi.org/10.1021/jacs.8b00461

This Article is brought to you for free and open access by the Department of Chemistry at LSU Digital Commons. It has been accepted for inclusion in Faculty Publications by an authorized administrator of LSU Digital Commons.

For more information, please contact ir@lsu.edu. 
Authors

Garrett L. Sternhagen, Sudipta Gupta, Yueheng Zhang, Vijay John, Gerald J. Schneider, and Donghui Zhang 


\title{
Solution Self-Assemblies of Sequence-Defined Ionic Peptoid Block Copolymers
}

Garrett L. Sternhagen, ${ }^{\dagger}$ Sudipta Gupta,${ }^{\dagger}$ Yueheng Zhang, ${ }^{\S}$ Vijay John, ${ }^{\S *}$ Gerald J. Schneider ${ }^{\dagger *^{*}}$ and Donghui Zhang ${ }^{\text {** }}$

'Department of Chemistry and Macromolecular Studies Group, Louisiana State University, Baton Rouge, Louisiana 70803, United States

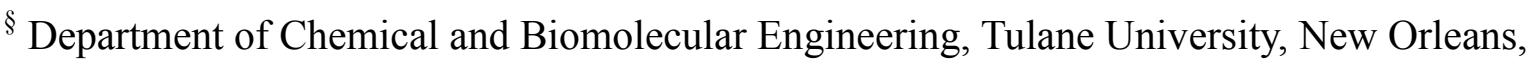
Louisiana 70118, United States

${ }^{\ddagger}$ Department of Physics, Louisiana State University, Baton Rouge, Louisiana 70803, United States

Corresponding to: dhzhang@1su.edu; gjschneider@1su.edu; vj@tulane.edu

\begin{abstract}
A series of amphiphilic ionic peptoid block copolymers where the total number (1 or 3) and position of ionic monomers along the polymer chain are precisely controlled have been synthesized by the sub-monomer method. Upon dissolution in water at $\mathrm{pH}=9$, the amphiphilic peptoids self-assemble into small spherical micelles having hydrodynamic radius in $\sim 5-10 \mathrm{~nm}$ range and critical micellar concentration (CMC) in the $0.034-0.094 \mathrm{mg} / \mathrm{mL}$ range. Small-angle neutron scattering (SANS) analysis of the micellar solutions revealed unprecedented dependence of the micellar structure on the number and position of ionic monomers along the chain. It was found that the micellar aggregation number $\left(N_{\mathrm{agg}}\right)$ and the micellar radius $\left(R_{\mathrm{m}}\right)$ both increase as the ionic monomer is positioned progressively away from the junction of the hydrophilic and hydrophobic segments along the polymer chain. By defining an ionic monomer position number (n) as the number of monomers between the junction and the ionic monomer, $N_{\text {agg }}$ exhibited a power law dependence on $n$ with an exponent of $\sim 1 / 3$ and $\sim 3 / 10$ for the respective singly and triply charged series. By contrast, $R_{\mathrm{m}}$ exhibited a weaker dependence on the ionic monomer position by a power law relationship with an exponent of $\sim 1 / 10$ and $\sim 1 / 20$ for the respective singly and triply charged series. Furthermore, $R_{\mathrm{m}}$ was found to scale with $N_{\mathrm{agg}}$ in a power-law relationship with an exponent of 0.32 for the singly charged series, consistent with a weakly charged ionic star-like polymer model in the unscreened regime. This study demonstrated a
\end{abstract}


unique method to precisely tailor the structure of small spherical micelles based on ionic block copolymers by controlling the sequence and position of the ionic monomer.

\section{INTRODUCTION}

Ubiquitous in nature and synthetic systems, electrostatic interactions have garnered much research interest for their importance in biological systems and their usefulness in the design of stimuli-responsive polymeric materials for various applications (e.g., water purification, oil recovery, drug delivery, etc.). Biomacromolecules (e.g., DNA/RNA, proteins, polysaccharide, proteoglycans) can be highly charged and use electrostatic interactions to maintain their structures and functions. ${ }^{1}$ In particular, proteins have precise control over the location of charged monomers along the chain, enabling the fine-tuning of the electrostatic interactions to access various sophisticated and well-defined higher order structures. The study of ionic macromolecules is complicated by the presence of many different electrostatic phenomena, relative to the charge neutral system. ${ }^{2}$ For example, as compared to neutral macromolecules in solution, ionic macromolecules can be affected by electrostatic repulsion, osmotic swelling, counter-ion condensation, as well as external effects such as changes in solution $\mathrm{pH}$ or salt content that confers charge screening. ${ }^{3-8}$

Ionic block copolymer (BCP) micelles are an intriguing class of nano-colloids due to the combination of their highly tunable structure and the ability to respond to external stimuli such as change in solvent $\mathrm{pH}$ or ionic strength. ${ }^{3-7}$ Similar to neutral micelles the exclusion of solvent by the hydrophobic segments of the polymer in the micellar core provides the driving force for their self-assembly into micelles in solution. While the equilibrium micellar structures in dilute solution are dependent on the degree of polymerization of the hydrophilic $\left(N_{\mathrm{A}}\right)$, hydrophobic segments $\left(N_{\mathrm{B}}\right)$, the fraction of charged monomers in the corona segment $(\alpha)$ and the solution salt concentration $\left(C_{\mathrm{s}}\right)^{2,3,9,10,11}$ kinetically trapped micellar assembly can lead to a diverse range of non-equilibrium morphologies. ${ }^{11-12}$

There have been theoretical studies on the scaling relationships for ionic BCP micelles in dilute solution. ${ }^{2,13}$ Under salt-free conditions, for star-like BCP micelles with sufficiently large fraction of charged monomers, the long-range Columbic repulsive interactions dominate over the short-range excluded volume interaction in the micellar corona. When the aggregation number of the micelle is small, the counter ions are mobile and distributed evenly throughout the micellar 
solution. In this so-called unscreened regime, the scaling theories predict that the power-law dependence of the micellar aggregation number $\left(N_{\mathrm{agg}}\right)$, the radius of the micellar core $\left(R_{\text {core }}\right)$ and the radius of the micellar corona $\left(R_{\text {corona }}\right)$ on $N_{\mathrm{A}}, N_{\mathrm{B}}$ and $\alpha$ in the following relationship: $N_{\mathrm{agg}} \sim$ $N_{\mathrm{B}}{ }^{2 / 3} N_{\mathrm{A}}{ }^{-1} \alpha^{-4 / 3}, R_{\text {core }} \sim N_{\mathrm{B}}^{5 / 9} N_{\mathrm{A}}^{-1 / 3} \alpha^{-4 / 9}$ and $R_{\text {corona }} \sim N_{\mathrm{B}}{ }^{2 / 9} N_{\mathrm{A}}{ }^{2 / 3} \alpha^{2 / 9}$. By contrast, for ionic BCP micelles with large aggregation number, the majority of the counter ions are concentrated in the micellar corona, resulting in increased osmotic pressure in the micellar corona and the stretching of the corona chains. ${ }^{9}$ In this so-called osmotic regime, the following scaling relationships have been predicted: $N_{\mathrm{agg}} \sim N_{\mathrm{B}}{ }^{2} N_{\mathrm{A}}^{-3} \alpha^{-3}, R_{\text {core }} \sim N_{\mathrm{B}} N_{\mathrm{A}}^{-1} \alpha^{-1}$ and $R_{\text {corona }} \sim N_{\mathrm{A}} \alpha^{1 / 2}$. In addition, star-like ionic BCP micelles can be considered similarly as ionic star-shape polymers with $f$ number of arms and $\alpha$ fraction of charged monomers per arm. ${ }^{14}$ In this model, the aggregation number of the micelle is equivalent to the number of arms $(f)$ in the star-shape polymer, whereas the degree of polymerization of the micellar corona segment is equivalent to the degree of polymerization of individual arm $(N)$ in a star-shape polymer. The theoretical study has predicted that the radius of the ionic star-shape polymers $[R(f)]$ to scale with $N, \alpha$ and $f$ in the following relationship: $R(f) \sim$ $N \alpha^{2 / 3} f^{1 / 3}$ in the unscreened regime and $R(f) \sim N \alpha^{1 / 2}$ in the osmotic regime. There are currently no theoretical efforts that systematically address the effect of the location of charged monomers along the chain on the micellar structures, which is the unique and key aspect of the current study.

In conventional ionic BCP micelles, the charge fraction in the micellar corona is typically controlled by copolymerization of ionic and neutral monomers, ${ }^{15}$ post polymerization modification to install ionic groups, ${ }^{16-18}$ and by changing the $\mathrm{pH}$ or ionic strength of the solution. ${ }^{3-7}$ These approaches are limited in the control over the spatial arrangement of the ionic monomers along the chain or in the micelle. There is currently no experimental or theoretical study on whether and how charges arranged in a spatially-defined manner along the BCP chain will affect the micellar structure. This is mainly due to the lack of suitable synthetic platforms that enable the systematic tuning of the location and number of ionic monomer along the chain. While polypeptides can be obtained in a sequence-defined manner, the hydrogen bonding and hydrophobic interaction often dominate and can induce the formation of secondary structures (e.g., helix or sheet) ${ }^{19-20}$ which introduces additional complexity towards the understanding of the electrostatic effects on the micellar structure. 
Peptoid polymers featuring $N$-substituted polyglycine backbones are structural mimic of polypeptides. $^{21-22}$ Because of $N$-substitution, peptoid polymers do not have stereogenic centers along the backbone and inter- or intramolecular hydrogen bonding relative to polypeptides. This allows various molecular interactions in the peptoid polymers to be systematically adjusted by controlling the $\mathrm{N}$-substituent structure. The advent of the sub-monomer method has enabled access to peptoid polymers where the monomer sequence is precisely defined. ${ }^{23-25}$ With farreaching applications ranging from biomaterials to energy ${ }^{21}$ to more fundamental structureproperty investigations, ${ }^{26-32}$ sequence-defined peptoid polymers represent a versatile platform for the study of a variety of nanoscale self-assembly processes. ${ }^{32-35}$

In view of the synthetic ease, structure tunability and absence of secondary structures, we reason that sequence-defined peptoid polymers represent an idea model to investigate the effect of sequence-defined charges on the ionic BCP self-assembly and structure in solution. Herein we design and synthesize a series of sequence-defined peptoid block copolymers where the number and position of ionic monomers along the polymer chain are precisely controlled. We have observed a significant effect of the position of ionic monomers on the micellar structure (e.g., aggregation number and micellar size). This study underscores the potential to precisely control and tailor the ionic micellar structure via the control of monomer sequence.

\section{RESULTS AND DISCUSSION}

Synthesis and Characterization of the Sequence-defined Ionic Peptoid BCPs. To achieve control over the monomer sequence, we have adopted the sub-monomer method in the synthesis of a series of sequence-defined amphiphilic peptoid block copolymers (BCPs) with precisely located ionic monomers in the hydrophilic segment. ${ }^{36}$ This series of peptoid BCPs are comprised of a total of twenty-five monomer units $(\mathrm{DP}=25)$ with three different types of $N$ substituents: $n$-decyl (hydrophobic), 2-methoxyethyl (neutral) and 2-carboxyethyl (ionic) (Figure 1A). The hydrophobic segment in each polypeptoid chain is conserved with five $N$ - $n$-decylglycine $\left(\mathrm{N}_{\mathrm{dc}}\right)$ monomers, whereas the hydrophilic segment has a total of twenty monomer units comprised of a single $\mathrm{N}$-2-carboxyethyl-glycine $\left(\mathrm{N}_{\mathrm{ce}}\right)$ and nineteen $\mathrm{N}$-2-methoxyethyl-glycine $\left(\mathrm{N}_{\text {me }}\right)$ residues in the singly charged series or three $\mathrm{N}_{\text {ce }}$ and seventeen $\mathrm{N}_{\text {me }}$ for the triply charged series. The monomer sequence in the hydrophilic segment is systematically varied to enable precise control of the ionic monomer position along the chain. In the singly charged series, the 
single ionic monomer is placed progressively towards the junction of the hydrophilic and hydrophobic segments (Sequence 1-5, Figure 1B). In the triply charged series, the three ionic monomers are spaced apart by a neutral monomer, and are placed increasingly close to the junction of the hydrophilic and hydrophobic segments (Sequence 6-8, Figure 1B). A chargeneutral sequence (Sequence 9, Figure 1B) has also been synthesized as a control sample for comparison with the singly and triply charged series. MALDI-TOF MS analysis of all peptoid samples revealed the presence of a major mass ion that corresponds to the molecular mass of targeted peptoid structures (Figure S1). In addition, several low intensity mass ions that are separated by $115 \mathrm{~m} / \mathrm{z}$ can also be seen, corresponding to some monomer deletion impurities. HPLC analysis revealed purity levels in $82 \%-95 \%$ range for all peptoid samples (Figure S2).

(A)

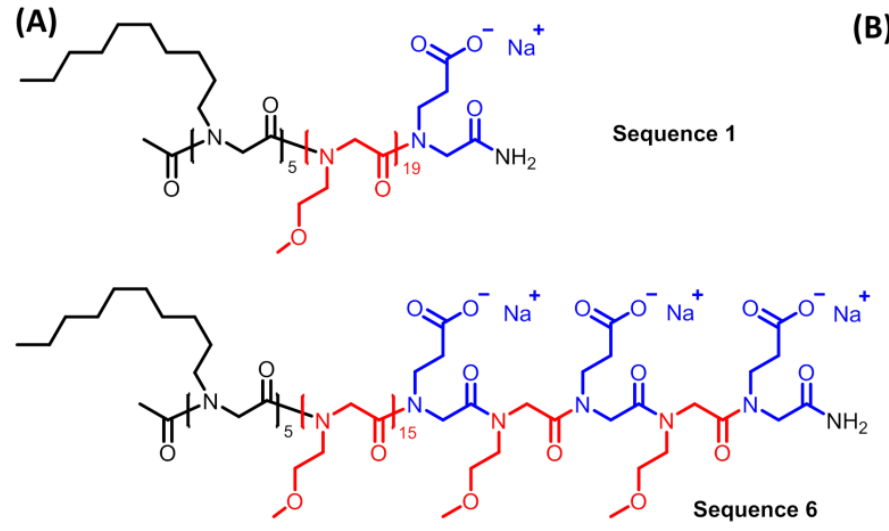

(B)

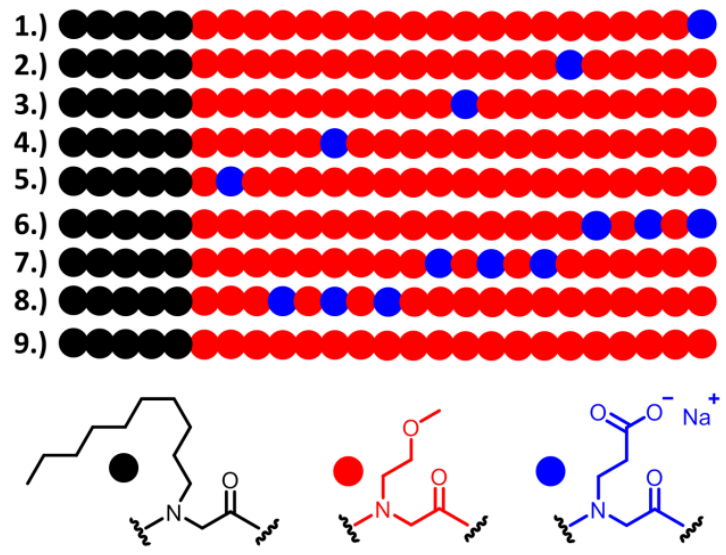

Figure 1. (A) Chemical structures of representative sequences of ionic peptoid block copolymers (1 or 6$)$ and (B) the sequence library showing the singly charged (1-5), triply charged series (6-8) and the charge-neutral sequence (9).

\section{Characterization of the Dilute Solution Structure of Sequence-defined Peptoid BCPs.}

All peptoid block copolymers shown in Figure 1 can be readily dissolved in aqueous solution in the $1 \times 10^{-4}-13 \mathrm{mg} / \mathrm{mL}$ concentration range. The aqueous solution was adjusted with 4 equivalents of $\mathrm{NaOH}$ per equivalent of $\mathrm{COOH}$ groups to ensure full deprotonation of all carboxyl groups $(\mathrm{pKa}=\sim 3-5)$ and the arrival at $\mathrm{pH}=9 .{ }^{37}$ The peptoid block copolymers form micelles with critical micelle concentration $(\mathrm{CMC})$ in the $0.034-0.094 \mathrm{mg} / \mathrm{mL}$ (i.e., $9.9 \times 10^{-6}-2.8 \times 10^{-5}$ M) range as determined by pyrene-1-carboxaldehyde fluorescence method (Figure S3-S4 and Table 1). ${ }^{38}$ At $\mathrm{pH} 9$, all carboxyl groups are expected to be fully deprotonated. While association 
of polymers can cause a shift in pKa of ionizable groups, this effect is expected to be relatively small based on reported literature. ${ }^{39}$ The zeta potential $(\zeta)$ measurement of the peptoids polymer solutions revealed that the micellar particles are negatively charged with $\zeta=-26--29 \mathrm{mV}$ for the singly charged series and $\zeta=-33--40 \mathrm{mV}$ for the triply charged series, consistent with the triply charged series bearing more negative charges than that singly charged series (Table 1 and Figure S4). No significant difference of zeta potential was seen for different sequences that have the same total number of ionic monomers. In comparison, the charge-neutral peptoid polymer (Sequence 9, Figure 1) exhibited a small positive zeta potential of $2.7 \mathrm{mV}$, which is attributed to association of proton or hydronium ion to the polymer.

Table 1. CMC, micellar radius $\left(R_{\mathrm{m}}\right)$ determined by CryoTEM image analysis, hydrodynamic radius of the micelles $\left(R_{\mathrm{h}}\right)$ and polydispersity determined by DLS analysis, and zeta potential $(\zeta)$ of various sequence-defined peptoid block copolymers (Sequence 1-9, Figure 1B) in dilute aqueous solution ( $\mathrm{pH}$ 9)

\begin{tabular}{|c|c|c|c|c|c|}
\hline $\begin{array}{c}\text { Sequence } \\
\#\end{array}$ & $\begin{array}{c}\text { CMC } \\
(\mathbf{m g} / \mathbf{m L})\end{array}$ & $\begin{array}{c}\boldsymbol{R}_{\mathbf{m}}(\mathbf{n m}, \\
\text { CryoTEM) }\end{array}$ & $\begin{array}{c}\boldsymbol{R}_{\mathbf{h}}(\mathbf{n m}, \\
\text { DLS MEM) }\end{array}$ & $\begin{array}{c}\text { PDI (DLS } \\
\text { MEM) }\end{array}$ & $\begin{array}{c}\text { Zeta Potential } \\
(\zeta, \mathbf{m V})\end{array}$ \\
\hline 1 & $0.072 \pm 0.005$ & $3.4 \pm 0.6$ & $7 \pm 2$ & $0.07 \pm 0.02$ & $-27 \pm 2$ \\
\hline 2 & $0.069 \pm 0.009$ & $3.9 \pm 0.3$ & $5 \pm 2$ & $0.10 \pm 0.05$ & $-27.9 \pm 0.6$ \\
\hline 3 & $0.070 \pm 0.005$ & $3.4 \pm 0.3$ & $8 \pm 2$ & $0.07 \pm 0.02$ & $-29 \pm 1$ \\
\hline 4 & $0.05 \pm 0.02$ & $3.4 \pm 0.3$ & $5 \pm 2$ & $0.11 \pm 0.04$ & $-26.5 \pm 0.7$ \\
\hline 5 & $0.094 \pm 0.005$ & $4.2 \pm 0.6$ & $9 \pm 2$ & $0.05 \pm 0.01$ & $-28 \pm 3$ \\
\hline 6 & $0.034 \pm 0.004$ & $3.0 \pm 0.4$ & $7 \pm 2$ & $0.07 \pm 0.02$ & $-35 \pm 3$ \\
\hline 7 & $0.037 \pm 0.007$ & $3.2 \pm 0.3$ & $7 \pm 2$ & $0.07 \pm 0.03$ & $-40 \pm 3$ \\
\hline 8 & $0.036 \pm 0.002$ & $2.9 \pm 0.3$ & $7 \pm 2$ & $0.07 \pm 0.02$ & $-33.5 \pm 0.9$ \\
\hline 9 & $0.09 \pm 0.01$ & $4.1 \pm 0.5$ & $11 \pm 2$ & $0.03 \pm 0.01$ & $2.7 \pm 0.1$ \\
\hline
\end{tabular}

Dynamic light scattering (DLS) analysis of a dilute aqueous solution of all peptoid polymer samples $(5 \mathrm{mg} / \mathrm{mL}, \mathrm{pH} 9)$ revealed a bimodal distribution with a major peak corresponding to hydrodynamic radius $\left(R_{\mathrm{h}}\right)$ of $\sim 5-11 \mathrm{~nm}$ and low polydispersity (PDI $=0.05-$ 0.11) (Figure S5 and Table 1), consistent with the formation of micelles. The minor peaks correspond to much larger aggregates. The correlation data were fitted using the maximum entropy method (MEM) ${ }^{40}$ to enable estimation of the size and relative abundance of larger 
particles. MEM analysis revealed the larger aggregate size $\left(R_{\mathrm{h}}\right)$ to be between $50-100 \mathrm{~nm}$ for ionic peptoid samples and $\sim 115 \mathrm{~nm}$ for the charge-neutral sample. As the intensity of scattered light scales as $I \alpha r^{6}$ ( $r$ = particle radius), the molar ratio of micellar particles to larger aggregates is estimated at $\sim 1 \times 10^{6}: 1$ for these samples. This indicates that the peptoid BCP series mainly form well-defined micelles at $0.5 \mathrm{wt} \%$ aqueous solution $(\mathrm{pH}=9)$ with negligible amounts of larger aggregates. While DLS analysis unambiguously confirmed the aggregation of the peptoid BCP series in aqueous solution, no significant difference in hydrodynamic size of the micelles was observed for these samples with varying sequences (Table 1).

CryoTEM analysis of the ionic peptoid polymers in dilute aqueous solution (0.5 wt $\%)$ revealed the predominant presence of spherical micelles (Figure 2). The spherical micelles are fairly uniform in size with the singly charged series having mean radii in the $3.4-4.2 \mathrm{~nm}$ range $(\mathrm{n}=50)$ and triply charged series having slightly smaller mean radii in the $2.9-3.2 \mathrm{~nm}$ range ( $\mathrm{n}$ =50) (Table 1). For the neutral peptoid sample, spherical micelles having a $4.1 \mathrm{~nm}$ mean radius (Sequence 9, Table 1) were observed to be the main species with occasional short worm-like nanostructures (Figure S6). 

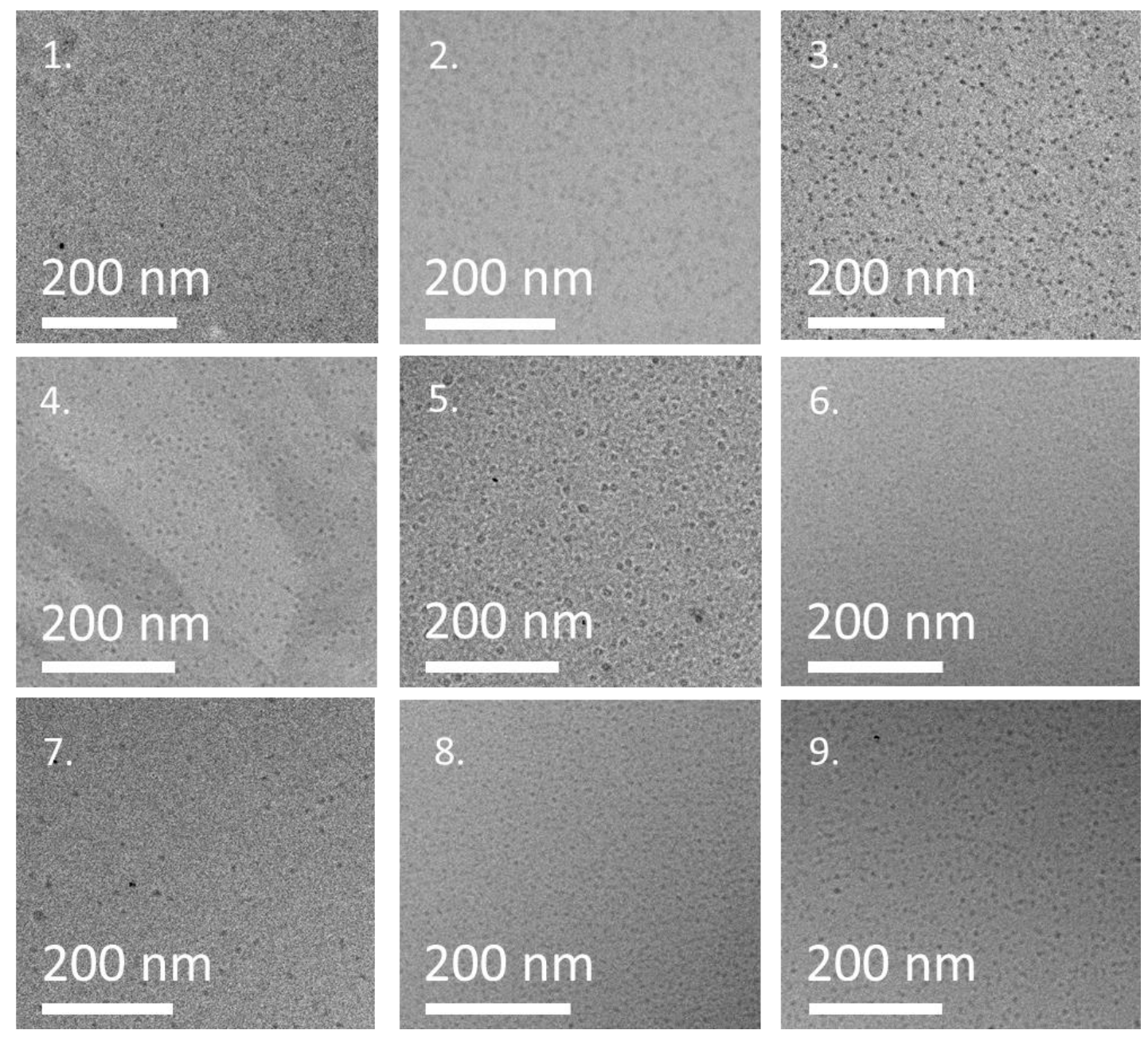

Figure 2. CryoTEM images of various sequence-defined ionic peptoid block copolymers (Sequence 1-9, Figure 1) in dilute aqueous solution $(5 \mathrm{mg} / \mathrm{mL}, \mathrm{pH} 9)$.

\section{Small-Angle Neutron Scattering (SANS) Analysis of the Micellar Structure in Dilute} Aqueous Solution. To further investigate the detailed structure of the micelles, SANS experiments were conducted on the series of sequence-defined peptoid micellar solutions (Entry $1-9$, Table 2) at a concentration of $0.45 \mathrm{vol} \%(0.5 \mathrm{wt} \%)$ and $\mathrm{pH}=9$ in $\mathrm{D}_{2} \mathrm{O}$. Measurements were conducted at the Spallation Neutron Source (EQ-SANS) and the High-Flux Isotope Reactor (Bio-SANS). For SANS analysis the neutron scattering length densities (SLDs) for each of the hydrophobic ( $\mathrm{N}_{\mathrm{dc}}$ monomers) and hydrophilic moiety ( $\mathrm{N}_{\mathrm{ce}}+\mathrm{N}_{\mathrm{me}}$ monomers) are calculated from the corresponding mass density following Murnen et al. ${ }^{37}$ For the SANS analysis the corresponding SLDs are kept constant for each of singly or triply charged system. All SANS data exhibited a Guinier-like low $q$ region, suggesting that the inter-particle interactions arising from the structure factor can be neglected at this concentration (Figure 3, S7 and S8). For the singly 
charged series shown in Figure 3, as the ionic monomer position along the peptoid polymer chain are shifted further from the junction of hydrophilic and hydrophobic segments, there is a notable increase in scattering intensity at low $q$, indicating an increase in aggregation number $\left(N_{\text {agg }}\right)$. A horizontal shift of the scattering curve toward the low $q$ region was also observed in the corresponding SANS plot indicating an increase in micellar radius $\left(R_{\mathrm{m}}\right)$. A similar trend was also observed for the micellar solution based on the triply charged peptoid polymer series (Figure S7).

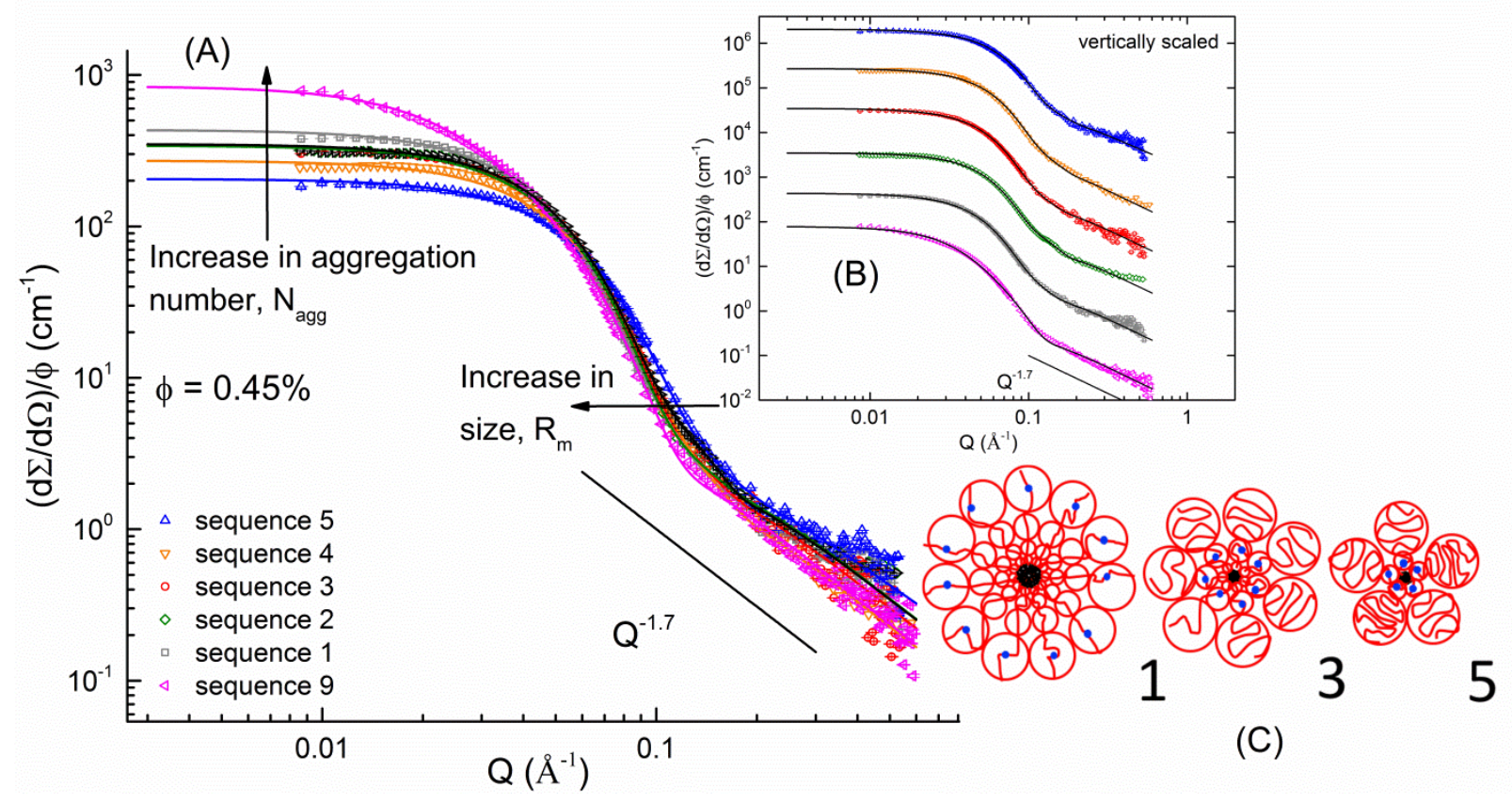

Figure 3. SANS scattering intensity, normalized by the polymer volume fraction, and analysis of the micellar solutions of sequence-defined peptoid block copolymers bearing a single ionic monomer (Sequence 1-5, Figure 1) in 0.45 vol\% $\mathrm{D}_{2} \mathrm{O}(\mathrm{pH} 9)$. Pictured are the fitted data for the singly charged peptoid polymer series (A) and the data vertically scaled by a constant for clarity (B). The solid lines correspond to fits using the core-shell model. ${ }^{41}$ At low $q$ an increase of scattering intensity corresponding to an increase in aggregation number is observed, while the general shift of the curves to lower $q$ indicates an overall increase in size as the ionic monomer is moved further away alone the chain from the junction of the hydrophilic and hydrophobic segments. (C) A cartoon representation of the micellar structure with respect to the ionic monomer position along the peptoid polymer chain. 
At high $q$, the scattering intensity exhibited a power law dependence on $q$ with a -1.7 exponent, suggesting a swollen coil in the micellar corona. This is in contrast to ionic block copolymer micelles with a highly charged corona segment, which were reported to exhibit a more rod-like or highly extended behavior where the exponent is close to -1 at the high $q$ region. ${ }^{9-10,42}$ The SANS data can be well-fitted with a core-shell form factor, using a neutral starlike micelle density profile, which was previously reported ${ }^{41}$ and briefly described in the Supporting Information. The micellar aggregation number $\left(N_{\mathrm{agg}}\right)$ and micellar size $\left(R_{\mathrm{m}}\right)$ were obtained from the fitting. The micellar radius of gyration $\left(R_{g}\right)$ was determined from the Guinier analysis of the SANS data (Figure S9-S10). The $q$ range was selected with the criteria of $R_{\mathrm{g}} \cdot q_{\max }$ $<<1$. The core radius of the micelle $\left(R_{c}\right)$, the corona thickness $\left(R_{\mathrm{m}}-R_{\mathrm{c}}\right)$, the core-corona interfacial area per polymer chain $(\sigma)$ and the corona volume occupied per polymer chain $(v)$ were calculated from the $N_{\mathrm{agg}}$ and $R_{\mathrm{m}}$, which will be further discussed (vide infra). All structural parameters of the micelles obtained from SANS analysis are summarized in Table 1 for different sequence-defined polypeptoids.

Table 2. Structural parameters of the micelles based on the sequence-defined ionic peptoid block copolymers (Sequence 1-9, Figure 1) as determined by SANS data analysis. The parameters include the particle aggregation number $\left(N_{\text {agg }}\right)$, the micellar radius $\left(R_{m}\right)$, the micellar radius of gyration $\left(R_{g}\right)$, the core radius $\left(R_{c}\right)$, the corona thickness $\left(R_{\mathrm{m}}-R_{\mathrm{c}}\right)$, the core-corona interfacial area per polymer chain $(\sigma)$ and the corona volume occupied per polymer chain $(v)$

\begin{tabular}{|c|c|c|c|c|c|c|c|c|}
\hline Sequence \# & $\begin{array}{c}\text { Ionic monomer } \\
\text { Position \# }\end{array}$ & $\boldsymbol{N}_{\text {agg }}$ & $\boldsymbol{R}_{\boldsymbol{m}}(\mathbf{n m})$ & $\boldsymbol{R}_{\boldsymbol{c}}(\mathbf{n m})$ & $\boldsymbol{R}_{\boldsymbol{m}}-\boldsymbol{R}_{\boldsymbol{c}}(\mathbf{n m})$ & $\boldsymbol{R}_{\boldsymbol{g}}(\mathbf{n m})$ & $\sigma\left(\mathbf{n m}^{2}\right)$ & $\boldsymbol{v}\left(\mathbf{n m}^{\mathbf{3}}\right)$ \\
\hline 1. & 20 & $28 \pm 2$ & $5.70 \pm 0.05$ & $2.30 \pm 0.05$ & $3.40 \pm 0.08$ & $4.02 \pm 0.04$ & $2.4 \pm 0.2$ & $26 \pm 2$ \\
\hline 2. & 15 & $25 \pm 1$ & $5.65 \pm 0.09$ & $2.12 \pm 0.06$ & $3.53 \pm 0.11$ & $3.70 \pm 0.07$ & $2.3 \pm 0.1$ & $29 \pm 1$ \\
\hline 3. & 11 & $23 \pm 1$ & $5.35 \pm 0.05$ & $2.13 \pm 0.03$ & $3.22 \pm 0.05$ & $3.56 \pm 0.05$ & $2.5 \pm 0.1$ & $26 \pm 1$ \\
\hline 4. & 6 & $18 \pm 1$ & $5.08 \pm 0.07$ & $1.96 \pm 0.03$ & $3.12 \pm 0.06$ & $3.24 \pm 0.05$ & $2.7 \pm 0.2$ & $29 \pm 2$ \\
\hline 5. & 2 & $13 \pm 1$ & $4.47 \pm 0.04$ & $1.80 \pm 0.04$ & $2.67 \pm 0.06$ & $2.88 \pm 0.03$ & $3.1 \pm 0.3$ & $27 \pm 2$ \\
\hline 6. & $16,18,20$ & $18 \pm 1$ & $4.50 \pm 0.03$ & $1.95 \pm 0.03$ & $2.55 \pm 0.04$ & $3.19 \pm 0.03$ & $2.7 \pm 0.2$ & $20 \pm 1$ \\
\hline 7. & $10,12,14$ & $17 \pm 2$ & $4.41 \pm 0.04$ & $1.93 \pm 0.07$ & $2.48 \pm 0.09$ & $3.15 \pm 0.03$ & $2.8 \pm 0.4$ & $19 \pm 2$ \\
\hline 8. & $4,6,8$ & $12 \pm 1$ & $4.24 \pm 0.03$ & $1.71 \pm 0.04$ & $2.53 \pm 0.06$ & $2.88 \pm 0.04$ & $3.1 \pm 0.3$ & $25 \pm 2$ \\
\hline 9. & $\mathrm{n} / \mathrm{a}$ & $52 \pm 2$ & $6.42 \pm 0.05$ & $2.80 \pm 0.09$ & $3.62 \pm 0.12$ & $4.52 \pm 0.04$ & $1.9 \pm 0.1$ & $19 \pm 1$ \\
\hline
\end{tabular}


The micelles based on the charge-neutral peptoid BCP (Table 2) have a significantly higher aggregation number $\left(N_{\mathrm{agg}}=52 \pm 2\right)$ relative to the singly $\left(N_{\mathrm{agg}}=13 \pm 1-28 \pm 2\right)$ or triply charged series $\left(N_{\text {agg }}=12 \pm 1-18 \pm 1\right)$, while the micellar radius $\left(R_{\mathrm{m}}=6.42 \pm 0.05 \mathrm{~nm}\right)$ is moderately larger than those of the charged micelles $\left(R_{\mathrm{m}}=4.47 \pm 0.04-5.70 \pm 0.05 \mathrm{~nm}\right.$ for the singly charged series and $R_{\mathrm{m}}=4.24 \pm 0.03-4.50 \pm 0.03 \mathrm{~nm}$ for the triply charged series) (Table 2). These results are consistent with an early SANS study of the polystyrene-polyisoprene (PS-PI) micelle having a single charge monomer per chain residing at the core-corona interface of the micelles. ${ }^{43}$ The PS-PI micelles having the charged monomers were shown to have significantly smaller aggregation number $\left(N_{\mathrm{agg}}=47\right)$ and moderately reduced micellar size $\left(R_{\mathrm{m}}=10 \mathrm{~nm}\right)$ than the charge-neutral micellar analogs $\left(N_{\text {agg }}=90, R_{\mathrm{m}}=13.2 \mathrm{~nm}\right)$. The radius of gyration $\left(R_{\mathrm{g}}\right)$ follows the similar trend as that of $R_{\mathrm{m}}$ with the neutral micelles being larger $\left(R_{\mathrm{g}}=4.52 \pm 0.04 \mathrm{~nm}\right)$ than those of the charged micelles $\left(R_{\mathrm{g}}=2.88 \pm 0.03-4.02 \pm 0.04 \mathrm{~nm}\right.$ for the singly charged series and $R_{\mathrm{g}}=$ $2.88 \pm 0.04-3.19 \pm 0.03 \mathrm{~nm}$ for the triply charged series) (Table 2). The dimensionless shape parameter defined as the ratio of $R_{\mathrm{g}}$ to $R_{\mathrm{h}}$ is in the $0.3 \pm 0.1-0.7 \pm 0.2$ range for all micelles. They are lower than the theoretical prediction for a hard sphere $(0.77)$. This could be due to the difference in solvent penetration into the micellar core and corona or the segmental density difference in the micelles, resulting in more complex hydrodynamic interactions, as previously reported on microgels or porous spheres. ${ }^{44-49}$

Assuming all micelles form a dense core, the micellar core radius can be calculated by using $R_{\mathrm{c}}=\left(3 N_{\mathrm{agg}} M_{\mathrm{w}, \mathrm{core}} / 4 \pi \rho_{\text {core }} N_{\mathrm{a}}\right)^{1 / 3}$ and $N_{\mathrm{agg}}$ values obtained from SANS analysis. The micellar corona thickness defined as $R_{m}-R_{\mathrm{c}}$ can also be calculated. It was found that the neutral micelles have larger core radius $\left(R_{\mathrm{c}}=2.80 \pm 0.09 \mathrm{~nm}\right)$ and corona thickness $\left(R_{m}-R_{\mathrm{c}}=3.62 \pm 0.12 \mathrm{~nm}\right)$ relative to the singly charged $\left(R_{\mathrm{c}}=1.80 \pm 0.04-2.30 \pm 0.05 \mathrm{~nm}, R_{m}-R_{\mathrm{c}}=2.67 \pm 0.06-3.53 \pm 0.11 \mathrm{~nm}\right)$ or triply charged micelles $\left(R_{\mathrm{c}}=1.71 \pm 0.04-1.95 \pm 0.03 \mathrm{~nm}, R_{m}-R_{\mathrm{c}}=2.48 \pm 0.09-2.55 \pm 0.04 \mathrm{~nm}\right)$ (Table 2, Figure 5A-5B). To assess the aerial density of polymer chains at the core-corona interface, the packing area per chain at the core-shell interface $(\sigma)$ was calculated using $\sigma=$ $4 \pi R_{\mathrm{c}}{ }^{2} / N_{\text {agg. }}$. The neutral micelle has a smaller $\sigma\left(1.9 \pm 0.1 \mathrm{~nm}^{2}\right)$ than the singly $(\sigma=2.3 \pm 0.1-$ $\left.3.1 \pm 0.3 \mathrm{~nm}^{2}\right)$ or triply charged micelles $\left(\sigma=2.7 \pm 0.2-3.1 \pm 0.3 \mathrm{~nm}^{2}\right)$ (Figure 5C). The corona volume occupied per polymer chain $(v)$ has also been calculated using $v=N_{\mathrm{agg}} /\left(4 / 3 \pi R_{\mathrm{m}}{ }^{3}-\right.$ $4 / 3 \pi R_{c}{ }^{3}$ ) to allow for assessment of the volume density of polymer chains in the micellar corona. 
The neutral micelles have a much smaller $v\left(=19 \pm 1 \mathrm{~nm}^{3}\right)$ than all singly charged micelles $(v=$ $26 \pm 2-29 \pm 2 \mathrm{~nm}^{3}$ ) and the triply charged micelles (Sequence 8, Figure 1) with the ionic monomers positioned closest to the block junction along the chain $\left(v=25 \pm 2 \mathrm{~nm}^{3}\right)$ (Figure 5D). Interestingly, the other two triply charged micelles with the ionic monomers positioned further away from the block junction (Sequence 7 and 6, Figure 1) has comparable volume chain density $\left(v=19 \pm 2\right.$ and $\left.20 \pm 1 \mathrm{~nm}^{2}\right)$ as the neutral micelles. These results clearly suggest a significant role of electrostatic interactions in the micellar corona in the solution assemblies of ionic block copolymer even in a weakly charged system, and that the position and total number of ionic monomers along the hydrophilic segment (i.e., the monomer sequence) can be manipulated to precisely tailor the structure details of ionic micelles.
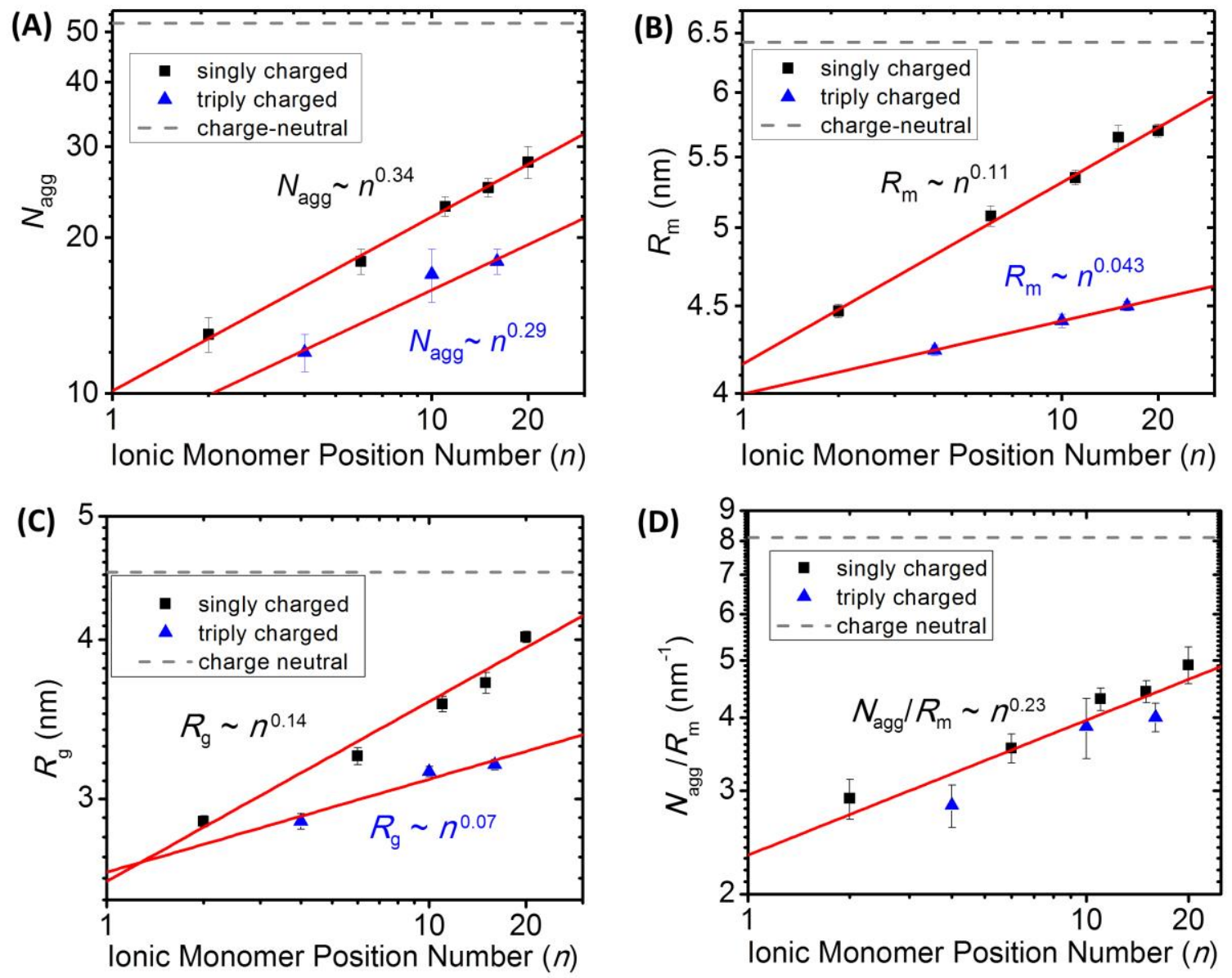

Figure 4. (A) Plots of the micellar aggregation number $\left(N_{\mathrm{agg}}\right)$, (B) the micellar radius $\left(R_{\mathrm{m}}\right)$, and (C) the radius of gyration of the micelles $\left(R_{\mathrm{g}}\right)$, and (D) the $N_{\mathrm{agg}} / R_{\mathrm{m}}$ ratio versus the position number of the ionic monomer $(n)$ in the sequence-defined peptoid polymer chain with a single 
charge ( $\boldsymbol{\square}$ ) or triple charges $(\boldsymbol{\Delta})$. The data for the neutral peptoid micelles are plotted as a dash line (---) in the respective figures for comparison. The position number is defined as the ionic monomer number along the hydrophilic segment counted by starting from the junction of the hydrophilic and hydrophobic segments. For the triply charged series, the position number in these plots is taken for the innermost ionic monomer. $N_{\mathrm{agg}}, R_{\mathrm{m}}$ and $R_{\mathrm{g}}$ are all determined from the fitting of SANS data with a core-shell model using a neutral star-like micelle density profile. ${ }^{41}$
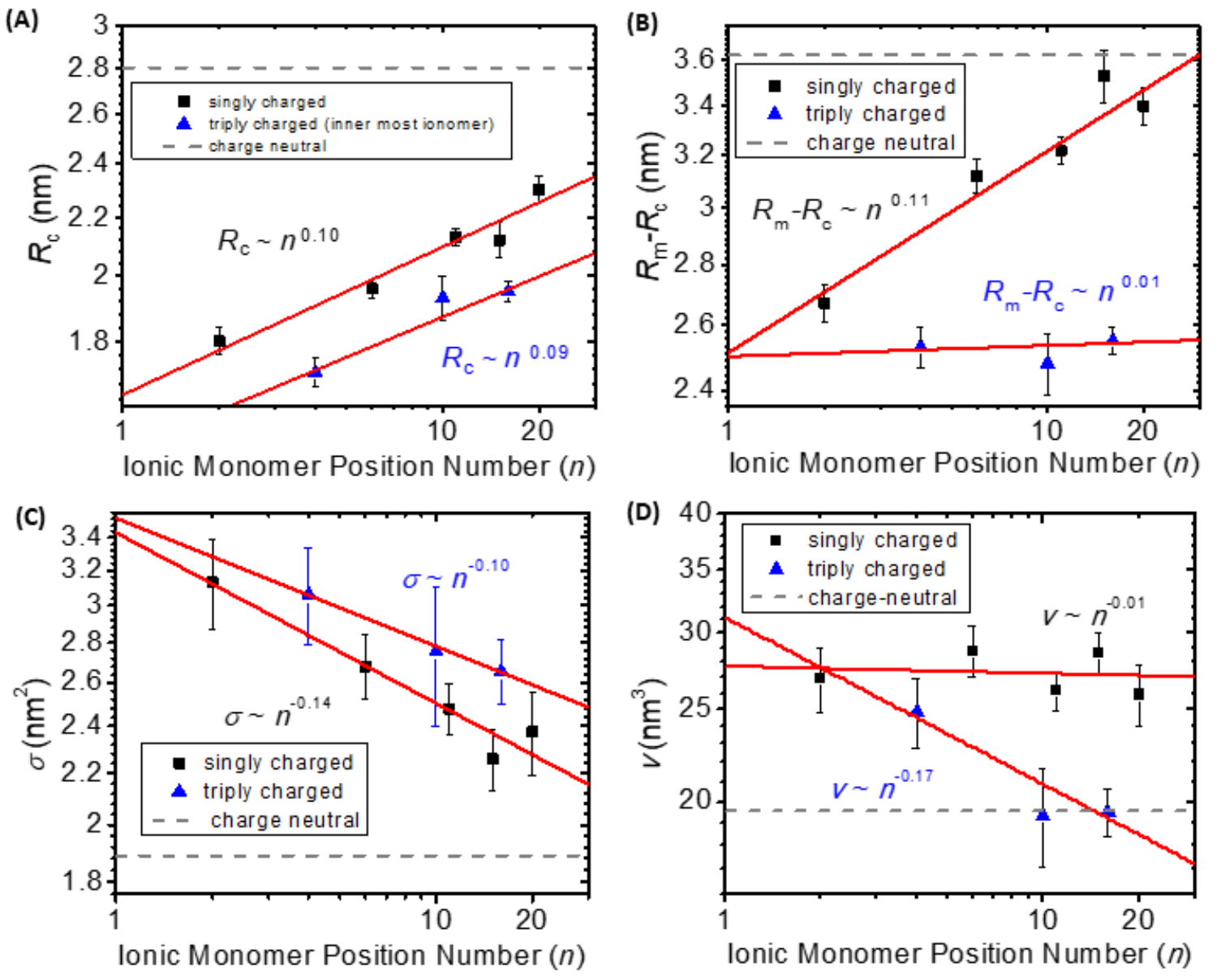

Figure 5. (A) Plots of the micellar core radius $\left(R_{\mathrm{c}}\right),(\mathrm{B})$ the micellar corona thickness $\left(R_{\mathrm{m}}-R_{\mathrm{c}}\right)$, (C) the core-corona interfacial area per polymer chain $(\sigma)$, and (D) the corona volume occupied per polymer chain $(v)$ versus the position number of the ionic monomer $(n)$ in the sequencedefined peptoids polymer chain with a single charge $(\boldsymbol{\square})$ or triple charges $(\boldsymbol{\Delta})$. The data for the neutral peptoid micelles are plotted as a dash line (---) in the respective figures for comparison. The position number is defined as the ionic monomer number along the hydrophilic segment 
counted by starting from the junction of the hydrophilic and hydrophobic segments. For the triply charged series, the position number in these plots is taken for the innermost ionic monomer.

\section{Investigation of the Sequence Effect on the Micellar Structure by Scaling Analysis.}

The sequence-defined nature of the peptoid block copolymers allows for precise description of each monomer's position along the chain. Considering the hydrophobic monomers as part of a compact core, the hydrophilic monomers in the micellar corona were numbered from 1 to 20 , starting from the first hydrophilic monomer residue at the junction of the hydrophilic and hydrophobic segments (Table 2 and Figure 1). The effect of ionic monomer position on the micellar structure has been assessed through the scaling relationship analysis of different structural parameters of micelles (i.e., $N_{\mathrm{agg}}, R_{\mathrm{m}}, R_{\mathrm{g}}, R_{\mathrm{c}}, R_{\mathrm{m}}-R_{\mathrm{c}}, \sigma$ and $v$ ) versus the ionic monomer position number $(n)$. For the triply charged micellar series, the analysis was conducted using the innermost, middle or outermost ionic monomer position number $(n)$, respectively. The results are summarized in Table 3.

Table 3. The prefactors and exponents for the power law relationship between various structural parameters $\left(N_{\mathrm{agg}}, R_{\mathrm{m}}, R_{\mathrm{g}}, N_{\mathrm{agg}} / R_{\mathrm{m}}, R_{\mathrm{c}}, R_{\mathrm{m}}-R_{\mathrm{c}}, \sigma\right.$ and $\left.v\right)$ of the sequence-defined peptoid block copolymer micelles (Sequence 1-9, Figure 1) and the ionic monomer position number $(n)$. The error bars of the prefactors and exponents were obtained from the data fitting using the power law function $\left(y=a x^{b}\right)$. For the triply charged series, the innermost, middle and outermost ionic monomer position are separately considered in the data fitting using the power law function.

\begin{tabular}{|c|c|c|c|c|c|c|c|c|}
\hline & \multirow{2}{*}{\multicolumn{2}{|c|}{ Singly charged series }} & \multicolumn{6}{|c|}{ Triply charged series } \\
\hline & & & \multicolumn{2}{|c|}{ Innermost } & \multicolumn{2}{|c|}{ Middle } & \multicolumn{2}{|c|}{ Outermost } \\
\hline & Prefactor & Exponent & Prefactor & Exponent & Prefactor & Exponent & Prefactor & Exponent \\
\hline$N_{\text {agg }}$ & $10.1 \pm 0.4$ & $0.34 \pm 0.01$ & $8.1 \pm 0.9$ & $0.29 \pm 0.04$ & $6 \pm 1$ & $0.37 \pm 0.06$ & $5 \pm 1$ & $0.44 \pm 0.08$ \\
\hline $\boldsymbol{R}_{\mathrm{m}}$ & $4.15 \pm 0.04$ & $0.107 \pm 0.004$ & $3.9950 \pm 0.0002$ & $0.04293 \pm 0.00002$ & $3.85 \pm 0.01$ & $0.054 \pm 0.002$ & $3.70 \pm 0.03$ & $0.065 \pm 0.003$ \\
\hline $\boldsymbol{R}_{\mathrm{g}}$ & $2.58 \pm 0.07$ & $0.14 \pm 0.01$ & $2.6 \pm 0.1$ & $0.07 \pm 0.02$ & $2.5 \pm 0.2$ & $0.09 \pm 0.03$ & $2.3 \pm 0.2$ & $0.11 \pm 0.04$ \\
\hline$N_{\mathrm{agg}} / \boldsymbol{R}_{\mathrm{m}}$ & $2.4 \pm 0.1$ & $0.23 \pm 0.02$ & $2.0 \pm 0.2$ & $0.25 \pm 0.04$ & $1.6 \pm 0.3$ & $0.31 \pm 0.06$ & $1.3 \pm 0.3$ & $0.37 \pm 0.08$ \\
\hline$R_{\mathrm{c}}$ & $1.65 \pm 0.05$ & $0.10 \pm 0.01$ & $1.51 \pm 0.06$ & $0.09 \pm 0.02$ & $1.39 \pm 0.09$ & $0.12 \pm 0.02$ & $1.3 \pm 0.1$ & $0.14 \pm 0.03$ \\
\hline$R_{\mathrm{m}}-R_{\mathrm{c}}$ & $2.51 \pm 0.09$ & $0.11 \pm 0.02$ & $2.50 \pm 0.08$ & $0.01 \pm 0.01$ & $2.5 \pm 0.1$ & $0.01 \pm 0.02$ & $2.5 \pm 0.1$ & $0.01 \pm 0.02$ \\
\hline$\sigma$ & $3.4 \pm 0.1$ & $-0.14 \pm 0.02$ & $3.53 \pm 0.06$ & $-0.10 \pm 0.01$ & $3.9 \pm 0.1$ & $-0.13 \pm 0.01$ & $4.2 \pm 0.2$ & $-0.15 \pm 0.02$ \\
\hline$v$ & $28 \pm 3$ & $-0.01 \pm 0.04$ & $31 \pm 4$ & $-0.17 \pm 0.05$ & $36 \pm 7$ & $-0.22 \pm 0.07$ & $40 \pm 10$ & $-0.26 \pm 0.09$ \\
\hline
\end{tabular}


Plotting of the aggregation number $\left(N_{\text {agg }}\right)$ versus the ionic monomer position number $(n)$ for the singly charged micellar series revealed an intriguing and unprecedented power-law relationship with an exponent of $0.34 \pm 0.01$ (Figure 4A, Table 3). The error bar of the exponent reflects the quality of the data fitting with the power- law function. A similar scaling relationship was also observed for the triply charged series with an exponent of $0.29 \pm 0.04$ using the position number of the innermost ionic monomer (which is closest to the junction of the hydrophilic and hydrophobic segments) in the analysis (Figure 4A). When the position number of the middle or outermost ionic monomer in the triply charged series is used, the exponent increased to $0.37 \pm 0.06$ and $0.44 \pm 0.08$ respectively (Figure S11-A). The micellar size $\left(R_{\mathrm{m}}\right)$ determined by SANS analysis was also found to exhibit a power-law dependence on $n$ but much weakly with an exponent of $0.107 \pm 0.004$ for the singly charged series, $0.04293 \pm 0.00002,0.054 \pm 0.002$ and $0.065 \pm 0.003$ for the triply charged series using the respective innermost, middle or outermost ionic monomer position number (Figure 4B and S11-B, Table 3). The radius of gyration of the micelles $\left(R_{\mathrm{g}}\right)$ also increases with $n$ similar to that of $R_{\mathrm{m}}$ with a power-law exponent of $0.14 \pm 0.01$ for the singly charged series (Figure 4C, Table 3 ). The $R_{\mathrm{g}}$ of the triply charged series scales more weakly with $n$ relative to the singly charged series, evidenced by the exponent of $0.07 \pm 0.02$, $0.09 \pm 0.03,0.11 \pm 0.04$ (Figure 4C and S11-C) for the former using the respective innermost, middle and outermost ionic monomer position number. It is noteworthy that when the $N_{\text {agg }} / R_{\mathrm{m}}$ ratio is plotted versus $n$ for the singly charged series or the triply charged series using the innermost ionic monomer position number, the two series can be collapsed into a master curve with the experimental accuracy and be described by a power-law function with an exponent of $0.23 \pm 0.04$ and a prefactor of $2.3 \pm 0.2$ (Figure 4D).

The micellar core radius $\left(R_{\mathrm{c}}\right)$ calculated from the $N_{\mathrm{agg}}$ using $R_{\mathrm{c}}=$ $\left(3 N_{\text {agg }} M_{\mathrm{w}, \text { core }} / 4 \pi \rho_{\text {core }} N_{\mathrm{a}}\right)^{1 / 3}$ was found to increase with $n$ in a power-law relationship (Figure 5A). The exponent $(0.10 \pm 0.01)$ for the singly charged series is comparable to that the triply charged series $(0.09 \pm 0.02,0.12 \pm 0.02,0.14 \pm 0.03$ using the respective innermost, middle or outermost ionic monomer position number in the scaling analysis) (Figure S11-E, Table 3). The micellar corona thickness $\left(R_{\mathrm{m}}-R_{\mathrm{c}}\right)$ also exhibited a power-law dependence on the ionic monomer position number with an exponent of $0.11 \pm 0.02$ for the singly charged series (Figure 5B, Table 3). By contrast, the micellar corona size of the triply charged series is essentially independent on $n$ with a close-to-zero exponent $(0.01 \pm 0.01,0.01 \pm 0.02,0.01 \pm 0.02)$ (Figure $5 \mathrm{~B}$ and S11-F, Table 2). 
The core-corona interfacial area per polymer chain $(\sigma)$ was found to decrease with increasing ionic monomer position number for both the singly and triply charged micellar series with comparable power-law exponents $(-0.14 \pm 0.02$ for the former, $-0.10 \pm 0.01,-0.13 \pm 0.01$ and $0.15 \pm 0.02$ for the latter) (Figure 5C and S11-G, Table 3). The volume occupied per polymer chain in the corona $(v)$ were shown to remain nearly invariant with the change of the ionic monomer position for the singly charged micelles, evidenced by a close-to-zero exponent ($0.01 \pm 0.04$ ) in the scaling analysis (Figure 5D). By contrast, $v$ appears to be more sensitive to the ionic monomer position for the triply charged series. Increasing the position number resulted in a decrease of $v$ in a power-law relationship with exponents of $-0.17 \pm 0.05,-0.22 \pm 0.07$ and $0.26 \pm 0.09$ using the innermost, middle or outermost ionic monomer position, respectively (Figure 5D and S11-H, Table 3).

To better understand the electrostatic effect on the ionic peptoid micellar structure, we conducted additional scaling analysis in the framework of an ionic star-like polymer model. ${ }^{14}$ It was found that the micellar radius $\left(R_{\mathrm{m}}\right)$ and the micellar corona size $\left(R_{\mathrm{m}}-R_{\mathrm{c}}\right)$ both increases with increasing aggregation number $\left(N_{\text {agg }}\right)$ in a power law relationship with an exponent that is approximately $1 / 3$ [i.e., $R_{\mathrm{m}}=(1.9 \pm 0.1) \times N_{\mathrm{agg}}{ }^{0.32 \pm 0.02} ; R_{\mathrm{m}}-R_{\mathrm{c}}=(1.2 \pm 0.2) \times N_{\mathrm{agg}}{ }^{0.31 \pm 0.06}$ ] for the singly charged polypeptoid series (Figure 6). This scaling relationship is consistent with the theoretical prediction on the dependence of polymer radius $[R(f)]$ on the number of arms $(f)$ for ionic starlike polymers [i.e., $R(f) \sim f^{1 / 3}$ ] in unscreened regime where the equilibrium polymer size is obtained by balancing the electrostatic repulsion with the conformational free energy penalty due to the extension of the polymer arms. ${ }^{14}$ In this regime, the electrostatic interaction within the corona is considered unscreened with an infinite Debye screening length, which can be satisfied when the polymer arm is weakly charged (i.e., low fraction of ionic monomers) in dilute solution of ionic star-like polymers. By comparison, for neutral star-like polymers with $f$ arms, the polymer radius is more weakly dependent on $f$ with a $R(f) \sim f^{1 / 4}\left(\theta\right.$ solvent) or $f^{1 / 5}$ (good solvent) power law relationship. ${ }^{14}$ This indicates that the long-range electrostatic repulsion can cause stronger chain extension than the short-range non-electrostatic repulsion (i.e., excluded volume interaction). The singly charged sequence-defined peptoid block copolymers containing a $5 \%$ molar fraction of the ionic monomers in the hydrophilic segments in dilute aqueous solution $(0.5$ wt $\%, \mathrm{pH}=9$ ) effectively behave like an ionic star-like polymer in the unscreened regime. In addition, the low fraction of the ionic monomer content in the hydrophilic segments does not 
significantly perturb the global chain conformation in the corona, thus giving rise to $I \sim q^{-1.7}$ scaling relationship at the high $q$ region in the SANS profile which is typically observed for starlike micelles of neutral block copolymers or neutral star-shape polymers in good solvent. ${ }^{41,50-52}$
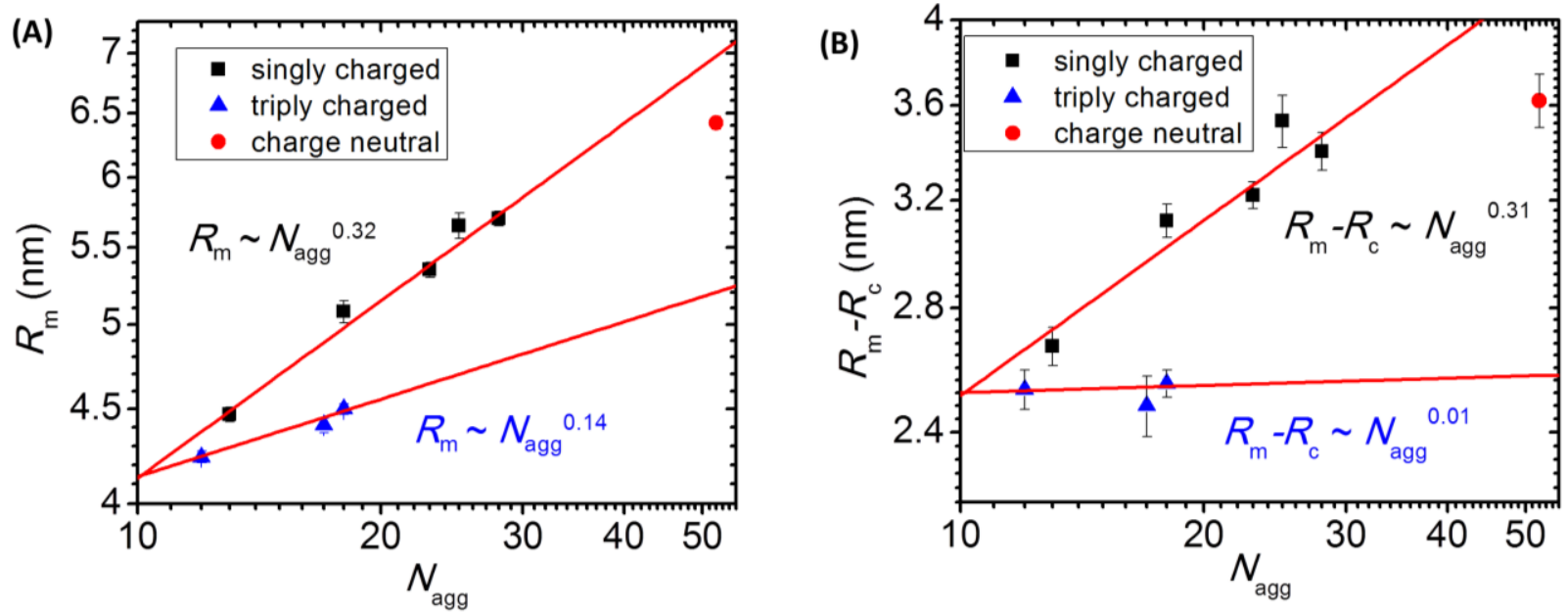

Figure 6. (A) Plots of the micellar radius $\left(R_{\mathrm{m}}\right)$ or $(\mathrm{B})$ the micellar corona thickness $\left(R_{\mathrm{m}}-R_{\mathrm{c}}\right)$ versus the aggregation number $\left(N_{\text {agg }}\right)$ for the micelles based on the singly and triply charged peptoid block copolymer series (Table 2).

For the triply charged peptoid BCP series, the micellar radius is exhibits a weaker dependence on the aggregation number in a power law relationship [i.e., $R_{\mathrm{m}}=$ $\left.(3.0 \pm 0.2) \times N_{\mathrm{agg}}^{0.14 \pm 0.03}\right]$ with an exponent of $0.14 \pm 0.03$ relative to the singly charged series (exponent=0.32 \pm 0.02 ) (Figure 6). Interestingly, the micellar corona size exhibited an even weaker power-law dependence on $N_{\mathrm{agg}}\left[\right.$ i.e., $\left.R_{\mathrm{m}}-R_{\mathrm{c}}=(2.4 \pm 0.3) \times N_{\mathrm{agg}}{ }^{0.01 \pm 0.05}\right]$ with an exponent of $0.01 \pm 0.05$ as compared to that of the singly charged series (exponent $=0.31 \pm 0.06$ ). This is most likely due to the increased charge content in the hydrophilic segment in the triply charged series (i.e., $15 \%$ molar fraction), resulting in increased trapping of the counter ions inside the micellar corona and screening of the electrostatic repulsion among the ionic monomers. The increased counter-ion concentration inside the corona will cause the corona chain to stretch through osmotic force. In this so-called osmotic regime, the equilibrium micellar size of ionic star-like polymers has been theoretically considered by balancing the free energy contribution of the osmotic force with the conformational free energy of stretched polymer chains, and predicted to be virtually independent on the number of arms in the ionic star-like polymers. Hence, the weak power law dependence of the micellar size $\left(R_{\mathrm{m}}\right)$ and corona size $\left(R_{\mathrm{m}}-R_{\mathrm{c}}\right)$ on the $N_{\text {agg }}$ for the triply 
charged peptoid series may represent a transition from the unscreened regime to the osmotic regime for this class of ionic star-like micelles. To fully understand the scaling relationship for the triply charged series, additional samples with different sequences needs to be analyzed.

It is clear that the electrostatic interaction encoded in the position and total number of the ionic monomers along the chain (i.e., the sequence information) has a notable impact on the selfassembled structures of the ionic peptoid block copolymers in dilute solution. In the singly charged sequence-defined peptoid BCP micelles, the electrostatic repulsion in the corona is systematically enhanced due to increased proximity of ionic monomers at the core-corona interface of the micelles, as the ionic monomer is placed progressively closer to the junction of the hydrophilic and hydrophobic segments along the chain. This results in a systematic decrease of the aggregation number and the micellar size accordingly. Similarly, increasing the total number of ionic monomers in the polymer chain further enhances the electrostatic repulsion in the micellar corona, leading to additional reduction of the aggregation number and micellar size in the triply charged micellar series relative to the singly charged micelles (Figure 4B). In addition, as the charge fraction is relatively low in the singly and triply charged series (i.e., 5 $\mathrm{mol} \%$ and $15 \mathrm{~mol} \%$ ), the chain conformation is not significantly perturbed from the swollen coil conformation. The micellar structure based on these sequence-defined ionic peptoid block copolymers represents an intermediate between the neutral star-like micelles and ionic star-like micelles (strongly charged). One can manipulate the position and number of ionic monomers along the chain to control the ionic micellar structure.

\section{CONCLUSIONS}

We have demonstrated that the electrostatic interactions are very important to the selfassembled structures of sequence-defined peptoid block copolymers containing ionic monomers. By simply controlling the monomer sequence, i.e., the positon and number of ionic monomers along the amphiphilic block copolymer chain, the resulting micellar structures (e.g., aggregation number and micellar size) can be precisely tailored. By placing increasing amount of ionic monomers closer to the junction of hydrophilic and hydrophobic segments along the chain, the micellar structures reorganize in aqueous solution to minimize electrostatic repulsive interaction. This study has demonstrated a novel strategy to access small star-like micelles (i.e., $R_{\mathrm{h}}$ in sub-10 $\mathrm{nm}$ ) having identical chemical composition but differing structural details by controlling the 
monomer sequences. Furthermore, the study has revealed a general principle that is potentially applicable to a variety of weakly charged soft matter self-assemblies, i.e., when the charge fraction is low in the system, the detailed structure of molecular assemblies can be tailored by the position and sequence of the ionic building blocks. This effect could be further explored towards the design of smart soft nano-colloids, tuning the fine structure of a drug carrier by the placement of a single well-chosen ionic functional group. Future efforts will be focused on investigating the effect of $\mathrm{pH}$, salt, solvent polarity on the micellar structure, and unravelling the scaling relationship of micellar structure with non-spherical interfaces.

ACKNOWLEDGEMENTS. GLS would like to thank Rafael Cueto, Doug Greer, Sunting Xuan, Ron Zuckermann and Jing Sun and for helpful conversations and instruction, as well as Ted Gauthier and Dong Liu. SG would like to thank Sai V. Pingali for assisting with the SANS experiments at the Bio-SANS instrument at High Flux Isotope Reactor (HIFR). This work is supported by the U.S. Department of Energy (DOE) under EPSCoR Grant No. DE-SC0012432 with additional support from the Louisiana Board of Regents. Work at the Molecular Foundry was supported by the Office of Science, Office of Basic Energy Sciences, of the U.S. Department of Energy under Contract No. DE-AC02-05CH11231. This research used resources at the High Flux Isotope Reactor and Spallation Neutron Source, a DOE Office of Science User Facility operated by the Oak Ridge National Laboratory.

\section{SUPPORTING INFORMATION AVAILABLE: Detailed experimental procedures,} representative MALDI-TOF MS and HPLC analysis of sequence-defined peptoid block copolymers, DLS-MEM analysis of the peptoid block copolymer solutions, determination of CMCs by fluorescence methods, plots of CMC, $R_{\mathrm{m}}, R_{\mathrm{h}}$, and zeta potential for different peptoid sequences, CryoTEM image showing the occasional worm-like micelles of the neutral peptoid polymer, SANS data of neutral or triply charged peptoid polymers in dilute aqueous solutions, and scaling analysis of micellar structure of triply charged peptoids block copolymer series using middle or outermost ionic monomer position numbers. This material is available free of charge via the Internet http://pubs.acs.org. 


\section{REFERNCES}

1. de Graff, Adam M. R.; Hazoglou, Michael J.; Dill, Ken A., Highly Charged Proteins: The Achilles' Heel of Aging Proteomes. Structure 2016, 24 (2), 329-336.

2. Borisov, O. V.; Zhulina, E. B.; Leermakers, F. A. M.; Müller, A. H. E., Self-Assembled Structures of Amphiphilic Ionic Block Copolymers: Theory, Self-Consistent Field Modeling and Experiment. In Self Organized Nanostructures of Amphiphilic Block Copolymers I, Müller, A. H. E.; Borisov, O., Eds. Springer Berlin Heidelberg: Berlin, Heidelberg, 2011; pp 57-129.

3. Förster, S.; Hermsdorf, N.; Böttcher, C.; Lindner, P., Structure of Polyelectrolyte Block Copolymer Micelles. Macromolecules 2002, 35 (10), 4096-4105.

4. Guenoun, P.; Davis, H. T.; Tirrell, M.; Mays, J. W., Aqueous Micellar Solutions of Hydrophobically Modified Polyelectrolytes. Macromolecules 1996, 29 (11), 3965-3969.

5. Khougaz, K.; Astafieva, I.; Eisenberg, A., Micellization in Block Polyelectrolyte Solutions. 3. Static Light Scattering Characterization. Macromolecules 1995, 28 (21), 71357147.

6. Laaser, J. E.; Jiang, Y.; Sprouse, D.; Reineke, T. M.; Lodge, T. P., pH- and IonicStrength-Induced Contraction of Polybasic Micelles in Buffered Aqueous Solutions. Macromolecules 2015, 48 (8), 2677-2685.

7. Lee, A. S.; Bütün, V.; Vamvakaki, M.; Armes, S. P.; Pople, J. A.; Gast, A. P., Structure of pH-Dependent Block Copolymer Micelles: Charge and Ionic Strength Dependence. Macromolecules 2002, 35 (22), 8540-8551.

8. Gupta, S.; Stellbrink, J.; Zaccarelli, E.; Likos, C. N.; Camargo, M.; Holmqvist, P.; Allgaier, J.; Willner, L.; Richter, D., Validity of the Stokes-Einstein Relation in Soft Colloids up to the Glass Transition. Phys. Rev. Lett. 2015, 115 (12), 128302.

9. Guenoun, P.; Muller, F.; Delsanti, M.; Auvray, L.; Chen, Y. J.; Mays, J. W.; Tirrell, M., Rodlike Behavior of Polyelectrolyte Brushes. Phys. Rev. Lett. 1998, 81 (18), 3872-3875.

10. Zhang, L.; Barlow, R. J.; Eisenberg, A., Scaling Relations and Coronal Dimensions in Aqueous Block Polyelectrolyte Micelles. Macromolecules 1995, 28 (18), 6055-6066.

11. Moffitt, M.; Khougaz, K.; Eisenberg, A., Micellization of Ionic Block Copolymers. Acc. Chem. Res. 1996, 29 (2), 95-102.

12. Zhang, L.; Eisenberg, A., Multiple Morphologies of "Crew-Cut" Aggregates of Polystyrene-b-poly(acrylic acid) Block Copolymers. Science 1995, 268 (5218), 1728-1731. 
13. Zhulina, E. B.; Borisov, O. V., Theory of Block Polymer Micelles: Recent Advances and Current Challenges. Macromolecules 2012, 45 (11), 4429-4440.

14. Borisov, O. V.; Zhulina, E. B., Effects of ionic strength and charge annealing in starbranched polyelectrolytes. Eur. Phys. J. B 1998, 4 (2), 205-217.

15. Wright, D. B.; Patterson, J. P.; Pitto-Barry, A.; Cotanda, P.; Chassenieux, C.; Colombani, O.; O'Reilly, R. K., Tuning the aggregation behavior of $\mathrm{pH}$-responsive micelles by copolymerization. Polym. Chem. 2015, 6 (14), 2761-2768.

16. Crichton, M. A.; Bhatia, S. R., Small-angle neutron scattering of poly(styrene)/poly(acrylic acid-ethyl acrylate) copolymers: The effect of the degree of hydrolysis of the poly(acrylic acid-ethyl acrylate) block. J. Appl. Polym. Sci. 2004, 93 (2), 490497.

17. Kulebyakina, A. I.; Lysenko, E. A.; Chelushkin, P. S.; Kabanov, A. V.; Zezin, A. B., Self-assembly of an amphiphilic diblock copolymer in aqueous solutions: Effect of linear charge density of an ionogenic block. Polymer Science Ser. A. 2010, 52 (6), 574-585.

18. Lysenko, E. A.; Kulebyakina, A. I.; Chelushkin, P. S.; Rumyantsev, A. M.; Kramarenko, E. Y.; Zezin, A. B., Polymer Micelles with Hydrophobic Core and Ionic Amphiphilic Corona. 2. Starlike Distribution of Charged and Nonpolar Blocks in Corona. Langmuir 2012, 28 (34), 12663-12670.

19. Hamley, I. W., Self-assembly of amphiphilic peptides. Soft Matter 2011, 7 (9), $4122-$ 4138.

20. Trent, A.; Marullo, R.; Lin, B.; Black, M.; Tirrell, M., Structural properties of soluble peptide amphiphile micelles. Soft Matter 2011, 7 (20), 9572-9582.

21. Gangloff, N.; Ulbricht, J.; Lorson, T.; Schlaad, H.; Luxenhofer, R., Peptoids and Polypeptoids at the Frontier of Supra- and Macromolecular Engineering. Chem. Rev. 2016, 116 (4), 1753-1802.

22. Zhang, D.; Lahasky, S. H.; Guo, L.; Lee, C.-U.; Lavan, M., Polypeptoid Materials: Current Status and Future Perspectives. Macromolecules 2012, 45 (15), 5833-5841.

23. Knight, A. S.; Zhou, E. Y.; Francis, M. B.; Zuckermann, R. N., Sequence Programmable Peptoid Polymers for Diverse Materials Applications. Adv. Mater. 2015, 27 (38), 5665-5691.

24. Sun, J.; Zuckermann, R. N., Peptoid Polymers: A Highly Designable Bioinspired Material. ACS Nano 2013, 7 (6), 4715-4732. 
25. Rosales, A. M.; Segalman, R. A.; Zuckermann, R. N., Polypeptoids: a model system to study the effect of monomer sequence on polymer properties and self-assembly. Soft Matter 2013, 9 (35), 8400-8414.

26. Fetsch, C.; Flecks, S.; Gieseler, D.; Marschelke, C.; Ulbricht, J.; van Pée, K.-H.; Luxenhofer, R., Self-Assembly of Amphiphilic Block Copolypeptoids with C2-C5 Side Chains in Aqueous Solution. Macromol. Chem. Phys. 2015, 216 (5), 547-560.

27. Fetsch, C.; Gaitzsch, J.; Messager, L.; Battaglia, G.; Luxenhofer, R., Self-Assembly of Amphiphilic Block Copolypeptoids - Micelles, Worms and Polymersomes. Sci. Rep. 2016, 6, 33491.

28. Murnen, H. K.; Khokhlov, A. R.; Khalatur, P. G.; Segalman, R. A.; Zuckermann, R. N., Impact of Hydrophobic Sequence Patterning on the Coil-to-Globule Transition of Protein-like Polymers. Macromolecules 2012, 45 (12), 5229-5236.

29. Sanii, B.; Kudirka, R.; Cho, A.; Venkateswaran, N.; Olivier, G. K.; Olson, A. M.; Tran, H.; Harada, R. M.; Tan, L.; Zuckermann, R. N., Shaken, Not Stirred: Collapsing a Peptoid Monolayer To Produce Free-Floating, Stable Nanosheets. J. Am. Chem. Soc. 2011, 133 (51), 20808-20815.

30. Mannige, R. V.; Haxton, T. K.; Proulx, C.; Robertson, E. J.; Battigelli, A.; Butterfoss, G. L.; Zuckermann, R. N.; Whitelam, S., Peptoid nanosheets exhibit a new secondary-structure motif. Nature 2015, 526 (7573), 415-420.

31. Robertson, E. J.; Battigelli, A.; Proulx, C.; Mannige, R. V.; Haxton, T. K.; Yun, L.; Whitelam, S.; Zuckermann, R. N., Design, Synthesis, Assembly, and Engineering of Peptoid Nanosheets. Acc. Chem. Res. 2016, 49 (3), 379-389.

32. Sun, J.; Jiang, X.; Lund, R.; Downing, K. H.; Balsara, N. P.; Zuckermann, R. N., Selfassembly of crystalline nanotubes from monodisperse amphiphilic diblock copolypeptoid tiles. Proc. Natl. Acad. Sci. U.S.A. 2016, 113 (15), 3954-3959.

33. Jiang, X.; Sun, J.; Zuckermann, R.; Downing, K. H.; Balsara, N., Morphology Study of Phosphonated Peptoid Block Copolymer. Microsc. Microanal. 2016, 22 (S3), 1926-1927.

34. Sun, J.; Jiang, X.; Siegmund, A.; Connolly, M. D.; Downing, K. H.; Balsara, N. P.; Zuckermann, R. N., Morphology and Proton Transport in Humidified Phosphonated Peptoid Block Copolymers. Macromolecules 2016, 49 (8), 3083-3090. 
35. Sun, J.; Teran, A. A.; Liao, X.; Balsara, N. P.; Zuckermann, R. N., Nanoscale Phase Separation in Sequence-Defined Peptoid Diblock Copolymers. J. Am. Chem. Soc. 2013, 135 (38), 14119-14124.

36. Figliozzi, G. M.; Goldsmith, R.; Ng, S. C.; Banville, S. C.; Zuckermann, R. N., [25] Synthesis of N-substituted glycine peptoid libraries. Methods Enzymol. 1996, Volume 267, 437447.

37. Murnen, H. K.; Rosales, A. M.; Dobrynin, A. V.; Zuckermann, R. N.; Segalman, R. A., Persistence length of polyelectrolytes with precisely located charges. Soft Matter 2013, 9 (1), 90 98.

38. Goddard, E. D.; Turro, N. J.; Kuo, P. L.; Ananthapadmanabhan, K. P., Fluorescence probes for critical micelle concentration determination. Langmuir 1985, 1 (3), 352-355.

39. Yang, Y.; Mijalis, A. J.; Fu, H.; Agosto, C.; Tan, K. J.; Batteas, J. D.; Bergbreiter, D. E., Reversible Changes in Solution $\mathrm{pH}$ Resulting from Changes in Thermoresponsive Polymer Solubility. J. Am. Chem. Soc. 2012, 134 (17), 7378-7383.

40. Livesey, A. K.; Brochon, J. C., Analyzing the Distribution of Decay Constants in PulseFluorimetry Using the Maximum Entropy Method. Biophys. J. 1987, 52 (5), 693-706.

41. Gupta, S.; Camargo, M.; Stellbrink, J.; Allgaier, J.; Radulescu, A.; Lindner, P.; Zaccarelli, E.; Likos, C. N.; Richter, D., Dynamic phase diagram of soft nanocolloids. Nanoscale 2015, 7 (33), 13924-13934.

42. Stubenrauch, K.; Voets, I.; Fritz-Popovski, G.; Trimmel, G., pH and ionic strength responsive polyelectrolyte block copolymer micelles prepared by ring opening metathesis polymerization. J. Polym. Sci., Part A: Polym. Chem. 2009, 47 (4), 1178-1191.

43. Mendes, E.; Schädler, V.; Marques, C. M.; Lindner, P.; Wiesner, U., Electrostatics in the self-assembly of macromolecular surfactants. Europhys. Lett. 1997, 40 (5), 521-526.

44. Kunz, D.; Thurn, A.; Burchard, W., Dynamic light scattering from spherical particles. Colloid. Polym. Sci. 1983, 261 (8), 635-644.

45. Helmstedt, M.; Schäfer, H., Determination of sizes of spherical particles, prepared by dispersion polymerization of methyl methacrylate in non-aqueous medium, by analysis of the particle scattering and autocorrelation functions. Polymer 1994, 35 (16), 3377-3383. 
46. Hirzinger, B.; Helmstedt, M.; Stejskal, J., Light scattering studies on core-shell systems: determination of size parameters of sterically stabilized poly(methylmethacrylate) dispersions. Polymer 2000, 41 (8), 2883-2891.

47. Tande, B. M.; Wagner, N. J.; Mackay, M. E.; Hawker, C. J.; Jeong, M., Viscosimetric, Hydrodynamic, and Conformational Properties of Dendrimers and Dendrons. Macromolecules 2001, 34 (24), 8580-8585.

48. Sprouse, D.; Jiang, Y.; Laaser, J. E.; Lodge, T. P.; Reineke, T. M., Tuning Cationic Block Copolymer Micelle Size by pH and Ionic Strength. Biomacromolecules 2016, 17 (9), 2849-2859.

49. Schneider, F.; Balaceanu, A.; Feoktystov, A.; Pipich, V.; Wu, Y.; Allgaier, J.; PyckhoutHintzen, W.; Pich, A.; Schneider, G. J., Monitoring the Internal Structure of Poly(Nvinylcaprolactam) Microgels with Variable Cross-Link Concentration. Langmuir 2014, 30 (50), 15317-15326.

50. Lund, R.; Willner, L.; Stellbrink, J.; Radulescu, A.; Richter, D., Role of Interfacial Tension for the Structure of PEP-PEO Polymeric Micelles. A Combined SANS and Pendant Drop Tensiometry Investigation. Macromolecules 2004, 37 (26), 9984-9993.

51. Bekhradnia, S.; Diget, J. S.; Zinn, T.; Zhu, K.; Sande, S. A.; Nyström, B.; Lund, R., Charged Star Diblock Copolymers in Dilute Solutions: Synthesis, Structure, and Chain Conformations. Macromolecules 2015, 48 (8), 2637-2646.

52. Amann, M.; Willner, L.; Stellbrink, J.; Radulescu, A.; Richter, D., Studying the concentration dependence of the aggregation number of a micellar model system by SANS. Soft Matter 2015, 11 (21), 4208-4217. 